\title{
Iptakalim influences the proliferation and apoptosis of human pulmonary artery smooth muscle cells
}

\author{
QINGLIN LI, XIAOPEI YAN, HUI KONG, WEIPING XIE and HONG WANG \\ Department of Respiratory Medicine, The First Affiliated Clinical Medical College \\ of Nanjing Medical University, Nanjing, Jiangsu 210029, P.R. China
}

Received February 23, 2016; Accepted May 23, 2016

DOI: $10.3892 / \mathrm{mmr} .2016 .5333$

\begin{abstract}
The aim of the present study was to determine the effect of an ATP-sensitive $\mathrm{K}^{+}\left(\mathrm{K}_{\text {ATP }}\right)$ channel opener iptakalim (IPT) on the proliferation and apoptosis of human pulmonary artery smooth muscle cells (HPASMCs), and examine the potential value of IPT to hypoxic pulmonary hypertension $(\mathrm{HPH})$ at a cellular level. HPASMCs were divided into the control, ET-1, ET-1+IPT and ET-1+IPT+glibenclamide (GLI) groups. GLI was administered $30 \mathrm{~min}$ prior to ET-1 and IPT. The 4 groups were incubated with corresponding reagents for $24 \mathrm{~h}$. Cell viability was evaluated using a CCK-8 assay, cell proliferation by 5-ethynyl-2'-deoxyuridine (EdU) incorporation assay, and cell apoptosis via the expression of apoptosis-related proteins, i.e., Bcl-2-associated $\mathrm{X}$ protein (Bax) and B-cell lymphoma $2(\mathrm{Bcl}-2)$ using western blotting. We incubated HPASMCs with varying concentrations of ET-1 for 24, 48 and $72 \mathrm{~h}$, and found that cell survival rate was increased in a dose-dependent manner $(\mathrm{P}<0.05)$ rather than in a time-dependent manner $(\mathrm{P}>0.05)$. After co-incubation of HPASMCs with varying concentrations of IPT and ET-1 for $24 \mathrm{~h}$, the cell survival rate was decreased in a dose-dependent manner. The cell survival rate in the IPT+ET-1 group was significantly lower than that in the ET-1 group $(\mathrm{P}<0.05)$. The cell viability $(\mathrm{P}<0.05)$ and proliferation $(\mathrm{P}<0.05)$ in the ET-1 group were higher than those in the control group, and the expression of $\mathrm{Bax} / \mathrm{Bcl}-2$ was lower than the control group $(\mathrm{P}<0.05)$. The cell viability $(\mathrm{P}<0.05)$ and proliferation $(\mathrm{P}<0.05)$ in the ET-1+IPT group were lower than those in the ET-1 group, and the expression of Bax/Bcl-2 was higher than that in the ET-1 group $(\mathrm{P}<0.05)$. The cell viability $(\mathrm{P}<0.05)$ and proliferation $(\mathrm{P}<0.05)$ in the ET-1+IPT+GLI group were higher than those in the ET-1+IPT group, and the
\end{abstract}

Correspondence to: Dr Hong Wang, Department of Respiratory Medicine, The First Affiliated Clinical Medical College of Nanjing Medical University, 300 Guangzhou Road, Nanjing, Jiangsu 210029, P.R. China

E-mail: liql_1@163.com

Key words: hypoxic pulmonary hypertension, human pulmonary artery smooth muscle cells, apoptosis, ATP-sensitive $\mathrm{K}^{+}$channel expression of $\mathrm{Bax} / \mathrm{Bcl}-2$ was lower than that in the ET-1+IPT group $(\mathrm{P}<0.05)$. In conclusion, IPT inhibited ET-1-induced HPASMC proliferation and promoted cell apoptosis. Thus, it may play an important role in the treatment of $\mathrm{HPH}$.

\section{Introduction}

Hypoxic pulmonary hypertension ( $\mathrm{HPH})$ is a severe disease detrimental to human health. The pathophysiology of HPH is contraction and proliferation of human pulmonary artery smooth muscle cells (HPASMCs) as well as small pulmonary arterial remodeling (1). The pathogenesis mechanism of HPH is not well characterized and no effective therapy for HPH is currently available. Although calcium channel antagonists, prostacyclins, endothelin receptor antagonists and phosphodiesterase type 5 (PDE5) inhibitors may treat pulmonary hypertension, these drugs did not inhibit or reverse pulmonary vascular remodeling due to hypoxia $(2,3)$. Therefore, clinical use of these expensive drugs is limited.

Krick et al reported that the $\mathrm{K}^{+}$channels on the HPASMC membrane were closely associated with the vasomotor tone (4). The activity of $\mathrm{K}^{+}$channels on the HPASMC membrane decreased in hypoxia, leading to increased intracellular $\mathrm{K}^{+}$ concentration, decreased activities of caspases and nuclease, and decreased apoptosis of HPASMCs. On the other hand, decreased activity of $\mathrm{K}^{+}$channels may depolarize the cell membrane, open voltage-dependent $\mathrm{Ca}^{2+}$ channels and increase $\mathrm{Ca}^{2+}$ influx (5). Furthermore, the release of $\mathrm{Ca}^{2+}$ from sarcoplasmic reticulum increased free intracellular $\mathrm{Ca}^{2+}\left(\left[\mathrm{Ca}^{2+}\right]_{\text {cyt }}\right)$ and promoted vascular smooth muscle contraction $(2,3)$. Increase of $\left[\mathrm{Ca}^{2+}\right]_{\text {cyt }}$ is a second messenger for many proliferation factors, and may induce the transition from synthesis phase to mitosis phase, promoting cell proliferation and aggravating pulmonary vascular remodeling (6-8).

Currently, ATP-sensitive $\mathrm{K}^{+}\left(\mathrm{K}_{\text {ATP }}\right)$ is the only known compensatory open $\mathrm{K}^{+}$channel in ischemia and hypoxia, representing an important compensatory mechanism $(9,10)$. The $\mathrm{K}_{\text {ATP }}$ channels are a group of widely distributed inward rectifier $\mathrm{K}^{+}$channels, which are heterologous octamers $\left[(\mathrm{SUR} / \mathrm{Kir} 6 . \mathrm{x})_{4}\right]$ consisting of the inward rectifier $\mathrm{K}^{+}$channel Kir6.x family and sulfonylurea receptor (SUR) family (11).

Pulmonary artery endothelial cells may be injured in chronic hypoxia, creating an imbalance of vasoactive substances secreted by endothelial cells, and may affect the 
pulmonary artery (12). The expression of vasoconstrictors increased ET-1, angiotensin II (Ang II) and 5-hydroxytryptamine (5-HT), while the expression of vasodilators decreased prostaglandin $\mathrm{I}_{2}\left(\mathrm{PGI}_{2}\right)$, calcitonin gene-related peptide, adenosine and nitric oxide (NO). These vasoconstrictors act on $\mathrm{K}_{\mathrm{ATP}}$ channels to promote pulmonary artery smooth muscle contraction and increase pulmonary vascular resistance, thereby promoting HPASMC proliferation and pulmonary vascular remodeling leading to pulmonary hypertension. $\mathrm{K}_{\text {АТP }}$ channel is an important pathway of pulmonary hypertension. Therefore, $\mathrm{K}_{\mathrm{ATP}}$ channel opener is a promising novel drug for HPH.

Iptakalim (IPT) is a novel $\mathrm{K}_{\mathrm{ATP}}$ channel opener and glibenclamide (GLI) is an antagonist to $\mathrm{K}_{\mathrm{ATP}}$ channel. Wang reported that IPT could increase outward potassium current in rat pulmonary artery smooth muscle cell membrane (13). This could not only prevent rat pulmonary hypertension induced by hypoxia or ET-1, but also reverse pulmonary vascular remodeling and right ventricular hypertrophy in hypoxic rats, thus preventing rat pulmonary hypertension effectively (14). In addition, IPT could open $\mathrm{K}_{\text {ATP }}$ channels on rabbit pulmonary artery smooth muscle cell membrane, which inhibits $\mathrm{Ca}^{2+}$ influx and decrease cytoplasmic $\mathrm{Ca}^{2+}$ concentration, thus inhibiting ET-1-induced rabbit pulmonary artery smooth muscle cell contraction and proliferation (15).

Cell proliferation and apoptosis maintain homeostasis in normal cells. In B-cell lymphoma 2 (Bcl-2) gene family, $\mathrm{Bcl}-2$ is the first gene found to be associated with cell proliferation and apoptosis. Bcl-2 proteins are located on inner mitochondrial membrane, endoplasmic reticulum and nuclear membrane. The main biological function of $\mathrm{Bcl}-2$ is to prolong cell life, enhancing cell resistance to various apoptosisinducing factors. Since the finding by Oltvai et al (16) that Bcl-2-associated X protein (Bax) could accelerate apoptosis, the regulation of apoptosis by Bax has been under investigation. Bax formed heterodimers with anti-apoptosis Bcl-2 to inhibit Bcl-2 and induce cell apoptosis. Higher Bax/Bcl-2 ratio promoted cell apoptosis and vice versa (17).

In the present study, a cell proliferation/toxicity detection kit [Cell Counting Kit-8 (CCK-8)] and 5-ethynyl-2'-deoxyuridine (EdU) incorporation assay were used to determine the effect on HPASMC proliferation by ET-1, western blotting to evaluate the expression of $\mathrm{Bcl}-2$ and $\mathrm{Bax}$ to detect apoptosis. The potential therapeutic effect of IPT on HPH was clarified on the cellular level.

\section{Materials and methods}

Cell culture. HPASMCs were purchased from Sciencell Research Laboratories (Carlsbad, CA, USA). Cells were routinely maintained in the medium containing $2 \%$ fetal bovine serum, $1 \%$ smooth muscle cell growth supplement (SMCGS) and 1\% penicillin/streptomycin, and incubated in a humidified incubator at $37^{\circ} \mathrm{C}$ with $5 \% \mathrm{CO}_{2}$. The medium was replaced every other day. Cells were passaged every 2 days, and the cells of the 2nd-6th passage were used in the study.

Reagents. ET-1 (Sigma, St. Louis, MO, USA), IPT (Institute of Pharmacology and Toxicology, Academy of Military Medical Sciences), GLI (Sigma), CCK-8 kit (Beyotime Institute of
Biotechnology, Shanghai, China), rabbit anti-Bax polyclonal antibody and rabbit anti-Bcl-2 polyclonal antibody (both from Cell Signaling Technology, Inc., Danvers, MA, USA) were used.

HPASMC viability by CCK-8 assay. Adherent HPASMCs in the logarithmic phase were digested and inoculated in 96-well plates, $100 \mu 1 /$ well in triplicate. Drugs were added after cell adherence for $24 \mathrm{~h}$. CCK-8 solution was prepared in serum-free SMCM medium and $100 \mu$ l CCK- 8 medium was added into wells instead of medium followed by 2-h incubation. Subsequently, the absorbance values were measured at 450 and $620 \mathrm{~nm}$ with a microplate reader (Thermo Fisher, Shanghai, China).

Cell viability was calculated as $\left(\mathrm{OD}_{450}-\mathrm{OD}_{620}\right.$ in treatment group $) /\left(\mathrm{OD}_{450}-\mathrm{OD}_{620}\right.$ in control group) x $100 \%$. Experiments were performed in triplicate independently.

HPASMC proliferation by EdU incorporation assay. EdU incorporation assay was performed following the manufacturer's instructions. Briefly, HPASMCs in the logarithmic phase were digested and inoculated in a 24 -well plate with coverslip. Drugs of a pre-determined concentration were added after cell adherence, $50 \mu \mathrm{mol} / \mathrm{l} \mathrm{EdU}$ medium were added for 2-h incubation. EdU medium was then discarded, the cells were washed with phosphate-buffered saline (PBS) for $5 \mathrm{~min} \times 2$, fixed with $4 \%$ paraformaldehyde at room temperature (RT) for $30 \mathrm{~min}$, decolorized in $2 \mathrm{mg} / \mathrm{ml}$ glycine for $5 \mathrm{~min}$ and washed with PBS for $5 \mathrm{~min}$. Cell permeation was performed by incubating the cells with $0.5 \%$ Triton X-100 for 10 min followed by washing. Staining buffer (1X Apollo) was added and incubated in the dark at RT for $30 \mathrm{~min}$. The staining buffer was discarded, permeation reagent (PBS containing 0.5\% Triton X-100) was added and incubated for $10 \mathrm{~min}$ x 2-3 times. Permeation reagent was discarded, the cells were washed with methanol for 5 min, 1-2 times and then washed with PBS for 5 min. Staining solution (1X Hoechst 33342) was freshly prepared and added to wells for 30-min incubation in the dark at RT. The cells were washed 1-3 times and observed under a fluorescence microscope (EUROIMMUN, Lubeck, Germany). Cell images were taken randomly and the percentage of positive cells was calculated. The assay was performed in triplicate.

Western blotting for Bax and Bcl-3 in HPASMCs to assay apoptosis. Cells were collected for protein extraction and loaded on SDS-PAGE gel for electrophoresis under constant voltage $70 \mathrm{~V}$, and $120 \mathrm{~V}$ after protein migration into the separating gel. The proteins were transferred to PVDF membrane (Runwelltac, Shanghai, China) under a constant current $300 \mathrm{~mA}$ for $90 \mathrm{~min}$. The membrane was blocked in 5\% skimmed milk for $2 \mathrm{~h}$. Primary antibody (Bax, Bcl-2, 1:1,000; $\beta$-actin, 1:5,000) was added for incubation overnight in $4^{\circ} \mathrm{C}$. The following day, the membrane was washed with TBST for 10 min x 3 and then secondary antibody (horseradish peroxidase (HRP)-labelled goat anti-rabbit antibody, 1:10,000) was added and incubated at RT for $1 \mathrm{~h}$. The membrane was washed with TBST for $10 \mathrm{~min} \times 3$ and subjected to color development.

Statistical analysis. SPSS 13.0 software (IBM Corporation, Armonk, NY, USA) was used for statistical analysis. 


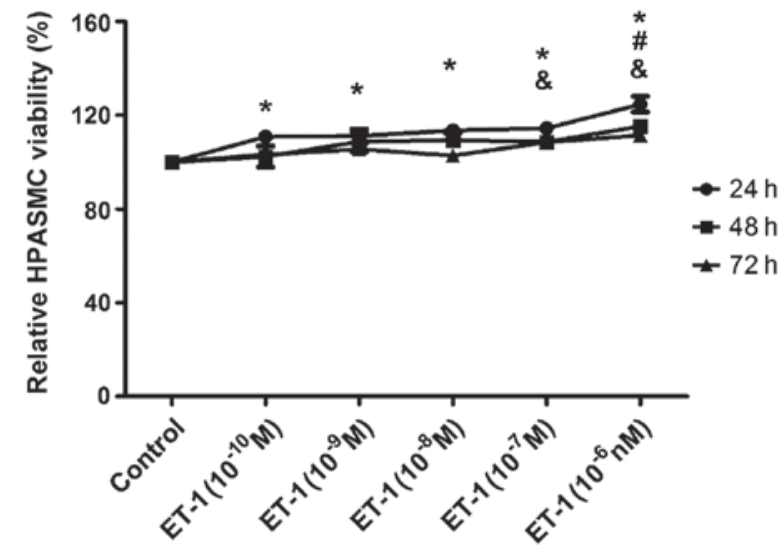

Figure 1. The effect on HPASMC viability by ET-1 (CCK-8 assay). *24-h relative survival, $\mathrm{P}<0.05$, vs. control group. ${ }^{*} 48$-h relative survival, $\mathrm{P}<0.05$, vs. control group. \&48-h relative survival, $\mathrm{P}<0.05$, vs. control group. HPASMC, human pulmonary artery smooth muscle cells.

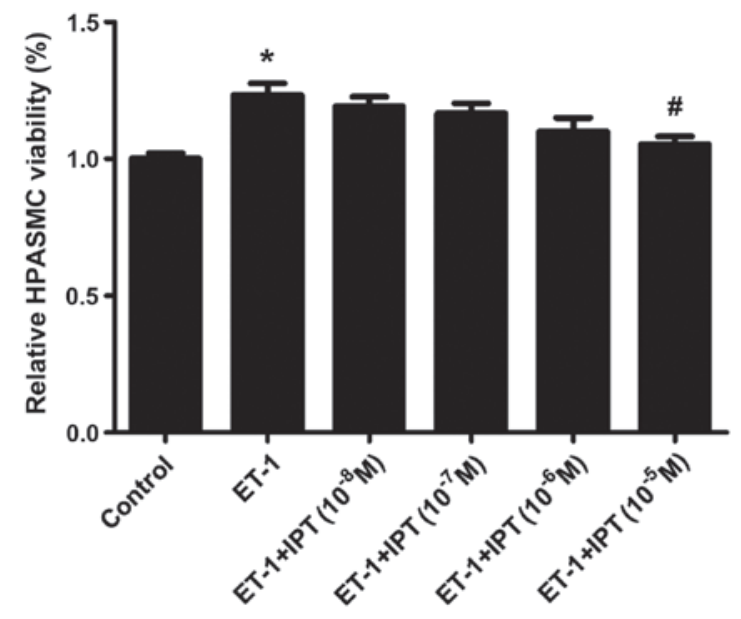

Figure 2. Effect on ET-1-induced HPASMC viability by IPT (CCK-8 assay). ${ }^{*} \mathrm{P}<0.05$, vs. control group. ${ }^{\#} \mathrm{P}<0.05$ vs. ET-1 group. HPASMC, human pulmonary artery smooth muscle cells; IPT, iptakalim.

Quantitative data are presented as mean \pm SD. One-way analysis of variance (ANOVA) was used for comparison between multiple groups, and the LSD method was used for comparison between two groups. Independent sample t-test was used in comparison between two groups. $\mathrm{P}<0.05$ was considered of statistical significance.

\section{Results}

Effect on HPASMC viability by ET-1. HPASMCs were incubated with ET-1 10-10, $10^{-9}, 10^{-8}, 10^{-7}$ and $10^{-6} \mathrm{M}$ for 24,48 and 72 h. As shown in Fig. 1, ET-1 increases HPASMC viability and the effect was enhanced with increasing ET-1 concentration. In addition, with different ET-1 concentrations, the HPASMC viability at 48 and $72 \mathrm{~h}$ was similar to that at $24 \mathrm{~h}$ and the effect on HPASMCs by ET-1 was not significantly time-dependent. Therefore, we selected ET-1 at $10^{-6} \mathrm{M}$ concentration for $24 \mathrm{~h}$ for further investigatation.

Effect on ET-1-induced HPASMC proliferation by IPT. HPASMCs were incubated with IPT $10^{-8}, 10^{-7}, 10^{-6}$ and $10^{-5} \mathrm{M}$,

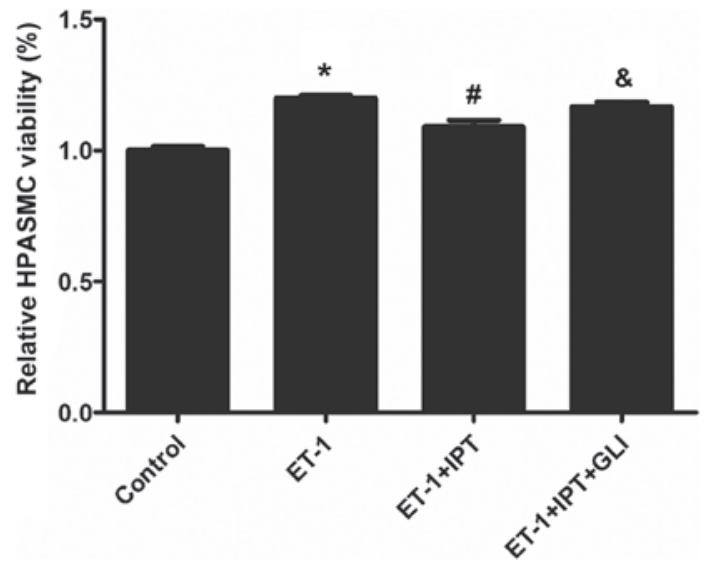

Figure 3. GLI partially reverses the effect on ET-1-induced HPASMC viability by IPT (CCK-8 assay). ${ }^{*} \mathrm{P}<0.05$, vs. control group. ${ }^{*} \mathrm{P}<0.05$ vs. ET-1 group. ${ }^{\&} \mathrm{P}<0.05$ vs. ET-1+IPT group. GLI, glibenclamide; HPASMC, human pulmonary artery smooth muscle cells; IPT, iptakalim.

and ET-1 $10^{-6} \mathrm{M}$ for $24 \mathrm{~h}$. CCK-8 assay was used to evaluate the change of HPASMC viability after incubation with varying concentrations of IPT. As shown in Fig. 2, IPT inhibited ET-1 induced increasing HPASMC viability and this effect was enhanced with increasing IPT concentration. In comparison with ET-1 alone, IPT $\left(10^{-5} \mathrm{M}\right)+\mathrm{ET}-1$ treatment decreased HPASMC viability significantly $(\mathrm{P}<0.05)$.

Effect on the ET-1-induced increase of HPASMC viability by IPT after blocking $K^{+}$channel. $\mathrm{K}^{+}$channel blocker GLI was used to block IPT-induced $\mathrm{K}^{+}$channel opening, to determine whether IPT was able to inhibit the ET-1-induced increase of HPASMC viability. Four groups were included in this analysis, i.e., control, ET-1, ET-1+IPT and ET-1+IPT+GLI groups, with ET-1 at $10^{-6} \mathrm{M}$, IPT at $10^{-5} \mathrm{M}$, GLI at $10^{-5} \mathrm{M}$ concentration. In the ET-1+IPT+GLI group, GLI was added $30 \mathrm{~min}$ prior to ET-1 and IPT, and the incubation time was $24 \mathrm{~h}$. As shown in Fig. 3, after blocking $\mathrm{K}^{+}$channel by GLI, HPASMC viability in the ET-1+IPT+GLI group was significantly higher than that in the ET-1+IPT group $(\mathrm{P}<0.05)$. This result demonstrated that GLI partially reversed the effect on ET-1-induced HPASMC viability by IPT, indicating that the inhibition of the ET-1-induced increase of HPASMC viability by IPT may occur through the opening $\mathrm{K}^{+}$channels.s

Twenty-four hours after incubation, EdU staining was performed for HPASMCs in all 4 groups. The percentage of EdU-stained cells in total cells was calculated on the basis of 5 fields (20X) randomly selected in each group. As shown in Figs. 4 and 5, the percentage of proliferated cells in the control, ET-1, ET-1+IPT and ET-1+IPT+GLI groups was 3.61 \pm 0.38 , $10.35 \pm 0.71,4.51 \pm 1.92$ and $10.50 \pm 0.58 \%$, respectively. After the addition of GLI, the percentage of proliferated cells in the ET-1+IPT+GLI group was significantly higher than that in the ET-1+IPT group $(\mathrm{P}<0.05)$.

Effect on ET-1-induced change of apoptotic protein expression in HPASMCs by IPT after blocking $K^{+}$channel. After incubation with drugs for $24 \mathrm{~h}$, the expression of apoptosis-related Bax and Bcl-2 in HPASMCs was evaluated by western blotting. As shown in Fig. 6, ET-1 downregulated Bax and upregulated 

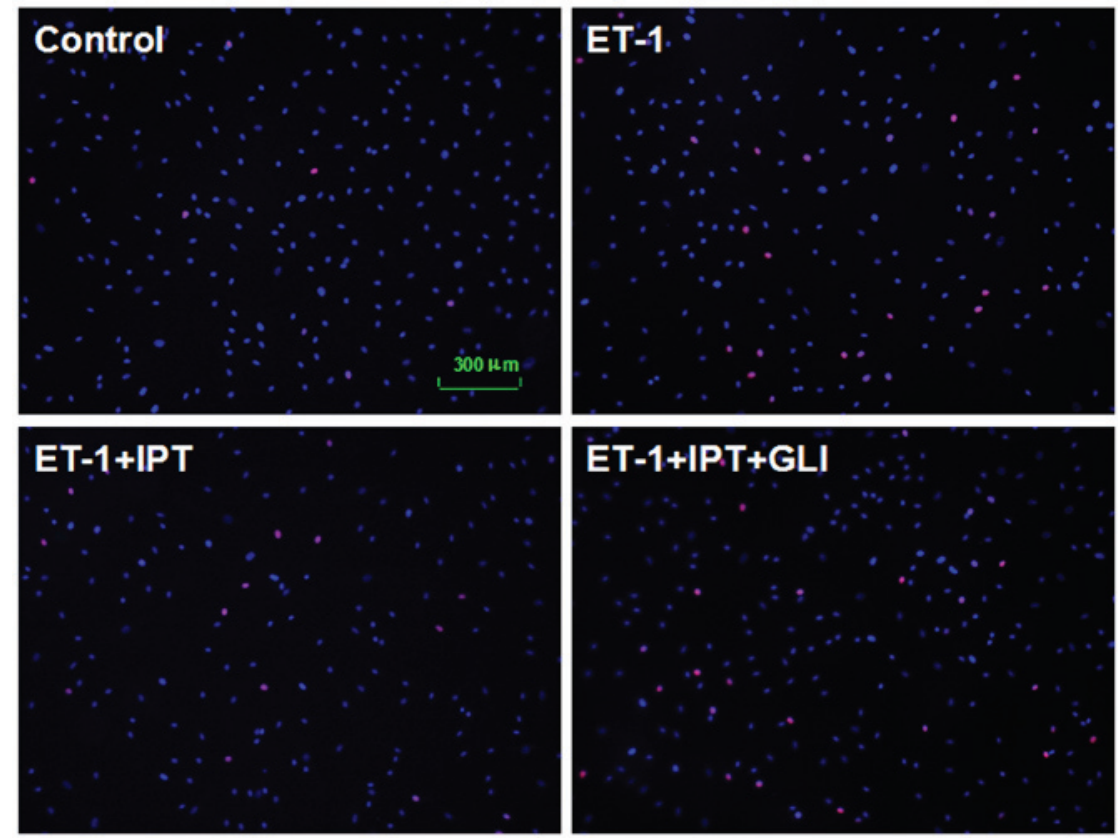

Figure 4. GLI reverses the effect on ET-1-induced HPASMC proliferation by IPT (EdU incorporation assay, n=3). GLI, glibenclamide; HPASMC, human pulmonary artery smooth muscle cells; IPT, iptakalim; EdU, 5-ethynyl-2'-deoxyuridine.

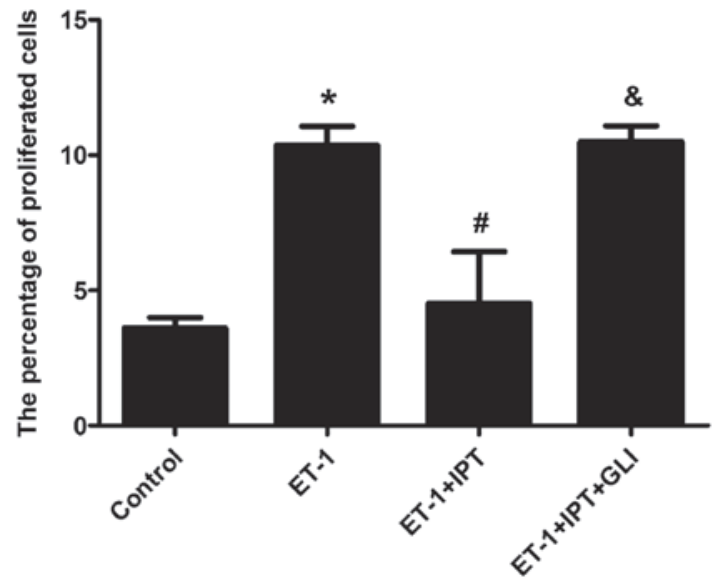

Figure 5. GLI reverses the effect on ET-1 induced HPASMC proliferation by IPT ( $\mathrm{n}=3) .{ }^{*} \mathrm{P}<0.05$ vs. control group. ${ }^{\text {"P }}<0.05$ vs. ET-1 group. ${ }^{\&} \mathrm{P}<0.05$ vs. ET-1+IPT group. GLI, glibenclamide; HPASMC, human pulmonary artery smooth muscle cells; IPT, iptakalim.

$\mathrm{Bcl}-2$, led to lower Bax/Bcl-2 ratio $(\mathrm{P}<0.05)$ vs. control group. IPT upregulated Bax and downregulated Bcl-2, leading to higher $\mathrm{Bax} / \mathrm{Bcl}-2$ ratio $(\mathrm{p}<0.05)$ vs. ET-1 group. GLI could block $\mathrm{K}^{+}$channels, downregulated Bax and upregulated Bcl-2, leading to lower $\mathrm{Bax} / \mathrm{Bcl}-2$ ratio $(\mathrm{P}<0.05)$ vs. ET-1+IPT group.

\section{Discussion}

Pulmonary hypertension is a disease detrimental to human health, its incidence is only second to hypertension and coronary heart disease in cardiovascular diseases (18-20). The pathophysiological characteristics are predominantly pulmonary vasoconstriction and pulmonary vascular remodeling. Pulmonary hypertension potentially causes rightsided heart failure and death (21). In China, the incidence of
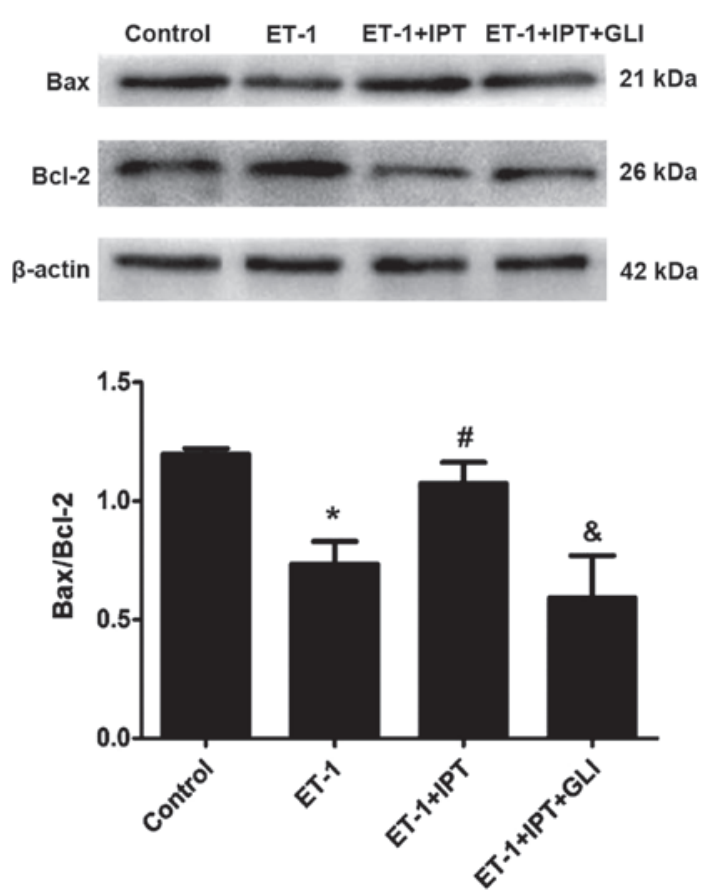

Figure 6. GLI reverses the effect on ET-1 induced change of apoptotic protein expression in HPASMCs by IPT (western blot, $n=3$ ). ${ }^{*} \mathrm{P}<0.05$ vs. control group. ${ }^{*} \mathrm{P}<0.05$ vs. ET- 1 group. ${ }^{\circledR} \mathrm{P}<0.05$ vs. ET-1+IPT group. GLI, glibenclamide; HPASMC, human pulmonary artery smooth muscle cells; IPT, iptakalim.

pulmonary hypertension due tohypoxia and respiratory diseases is on the increase, and the reasons include: i) smoking, chronic bronchitis and chronic obstructive pulmonary disease (COPD) due to cigarette smoking, common pulmonary diseases that lead to HPH; ii) the incidence of respiratory disorder during sleep is increasing due to an increase in obese population, with pulmonary hypertension due to higher pulmonary vascular 
resistance; and iii) high altitude pulmonary hypertension, a common chronic hypoxic pulmonary disease in China as compared to other countries (22). Therefore, the investigation of pathogenesis mechanism underlying $\mathrm{HPH}$ and development of new therapeutic drugs are of important clinical significance.

The pathogenesis mechanism of HPH is not well established. Currently, the main mechanism underlying higher pulmonary vascular resistance due to chronic hypoxia is pulmonary vascular proliferation and remodeling (23). On the one hand, hypoxia induces the production of reactive oxygen species in mitochondria and inhibits the activity of voltagegated $\mathrm{K}^{+}$channels on the HPASMC membrane leading to depolarization of the cell membrane and influx of extracellular $\mathrm{Ca}^{2+}$, which may cause vascular smooth muscle cell contraction. On the other hand, hypoxia may cause dysfunction in pulmonary artery endothelial cells, leading to the decreased production of vasodilator factors (NO and prostacyclin) and overexpression of vasoconstrictive and pro-proliferation factors (thromboxane A2 and ET-1). An imbalance between vasodilators and vasoconstrictors may cause increased small pulmonary arterial tone. The proliferation of endothelial cells, smooth muscle cells and fibroblasts may lead to small pulmonary artery remodeling and increased synthesis of extracellular matrix, such as collagen, elastin and fibronectin (24).

ET-1 is a vasoconstrictor synthetized and secreted by pulmonary vascular endothelial cells. Excess ET-1 may cause pulmonary vascular smooth muscle cell contraction and proliferation $(25,26)$. ET-1 binds to the endothelin-A $\left(\mathrm{ET}_{\mathrm{A}}\right)$ receptor, inhibit $\mathrm{G}$ protein $(\mathrm{Gi})$, adenylate cyclase or phospholipase $\mathrm{C}$ (PLC), and $\mathrm{K}_{\text {ATP }}$ channels (27), leading to a decreased outflow of intracellular $\mathrm{K}^{+}$, cell membrane depolarization, voltage-dependent $\mathrm{Ca}^{2+}$ channel opening, increased influx of extracellular $\mathrm{Ca}^{2+}$, release of $\mathrm{Ca}^{2+}$ in sarcoplasmic reticulum, which would increase free intracellular $\mathrm{Ca}^{2+}$, promoting the expression of the genes related to cell proliferation (c-Myc and c-Fos), and inducing cell proliferation (28).

In the present study, we stimulated HPASMCs with ET-1 to develop the model of HPASMC proliferation. We found that IPT inhibited ET-1 and induced HPASMC proliferation to promote HPASMC apoptosis. To verify whether the inhibition of ET-1-induced HPASMC proliferation by IPT was mediated through $\mathrm{K}_{\text {ATP }}$ channels, we blocked $\mathrm{K}_{\text {ATP }}$ channel with $\mathrm{K}_{\text {ATP }}$ channel blocker GLI and evaluated the effect on IPT. As shown in Figs. 4 and 5, in ET-1+IPT+GLI group, GLI could block IPT, thus IPT could not inhibit ET-1-induced HPASMC proliferation. This result confirms that IPT could inhibit ET-1 induced HPASMC proliferation through opening $\mathrm{K}_{\text {ATP }}$ channels.

It was reported that mitochondria was sensitive to hypoxia, mitochondrial dysfunction was closely associated with cell apoptosis and played important roles in the pathogenesis of HPH. Hypoxia could inhibit the release of cytochrome $c$ (cyt-c) from mitochondria into cytoplasm, thus inhibiting the mitochondrial apoptotic pathway, leading to HPASMC proliferation and pulmonary hypertension (29-32). The release of mitochondrial cyt- $c$ and other pro-apoptotic components was regulated by Bcl-2 family, upstream of the mitochondrial apoptosis pathway. Bcl-2 family proteins were classified into anti-apoptosis proteins (Bcl-2, Bcl-xL and Bcl-W) and pro-apoptosis proteins (Bax, Bcl-Xs and Bak). Among others, Bcl-2 and Bax were similar in structure and antagonistic to each other (33). Bcl-2 and Bax played important regulatory roles in the mitochondrial apoptosis pathway. The present findings demonstrate that ET-1 downregulated Bax and upregulated Bcl-2 in HPASMCs to inhibit cell apoptosis while IPT reversed the effect of ET-1, indicating that IPT regulated the proliferation and apoptosis of HPASMCs by increasing the Bax/Bcl-2 ratio. $\mathrm{K}_{\mathrm{ATP}}$ channel inhibitor GLI could partially reverse the effect of IPT, indicating that IPT could increase Bax/Bcl-2 ratio through opening the $\mathrm{K}_{\mathrm{ATP}}$ channel, and inhibited ET-1- induced HPASMC proliferation.

In conclusion, IPT inhibited ET-1-induced HPASMC proliferation and promoted apotosis through opening $\mathrm{K}_{\mathrm{ATP}}$ channels, therefore, it may be a promising novel drug for HPH.

\section{References}

1. Mandegar M, Yuan JX: Role of $\mathrm{K}^{+}$channels in pulmonary hypertension. Vascul Pharmacol 38: 25-33, 2002

2. Saji T, Myoishi M, Sugimura K, Tahara N, Takeda Y, Fukuda K, Olschewski H, Matsuda Y, Nikkho S and Satoh T: Efficacy and safety of inhaled iloprost in japanese patients with pulmonary arterial hypertension- insights from the IBUKI and AIR studies. Circ J 80: 835-842, 2016.

3. Provencher S and Granton JT: Current treatment approaches to pulmonary arterial hypertension. Can J Cardiol 31: 460-477, 2015.

4. Krick S, Platoshyn O, Sweeney M, Kim H and Yuan JX: Activation of $\mathrm{K}^{+}$channels induces apoptosis in vascular smooth muscle cells. Am J Physiol Cell Physiol 280: C970-C979, 2001.

5. Shimoda LA, Wang J and Sylvester JT: $\mathrm{Ca}^{2+}$ channels and chronic hypoxia. Microcirculation 13: 657-670, 2006.

6. Bonnet S and Archer SL: Potassium channel diversity in the pulmonary arteries and pulmonary veins: implications for regulation of the pulmonary vasculature in health and during pulmonary hypertension. Pharmacol Ther 115: 56-69, 2007.

7. Wang J, Juhaszova M, Rubin LJ and Yuan XJ: Hypoxia inhibits gene expression of voltage-gated $\mathrm{K}^{+}$channel $\alpha$ subunits in pulmonary artery smooth muscle cells. J Clin Invest 100: 2347-2353, 1997.

8. Moudgil R, Michelakis ED and Archer SL: The role of $\mathrm{K}^{+}$ channels in determining pulmonary vascular tone, oxygen sensing, cell proliferation, and apoptosis: implications in hypoxic pulmonary vasoconstriction and pulmonary arterial hypertension. Microcirculation 13: 615-632, 2006.

9. Wiener CM, Banta MR, Dowless MS, Flavahan NA and Sylvester JT: Mechanisms of hypoxic vasodilation in ferret pulmonary arteries. Am J Physiol 269: L351-L357, 1995.

10. Standen NB and Quayle JM: $\mathrm{K}^{+}$channel modulation in arterial smooth muscle. Acta Physiol Scand 164: 549-557, 1998.

11. Tang Y, Long CL, Wang RH, Cui W and Wang H: Activation of SUR2B/Kir6.1 subtype of adenosine triphosphate-sensitive potassium channel improves pressure overload-induced cardiac remodeling via protecting endothelial function. J Cardiovasc Pharmacol 56: 345-353, 2010.

12. Hampl V, Bíbová J, Banasová A, Uhlík J, Miková D, Hnilicková O, Lachmanová V and Herget J: Pulmonary vascular iNOS induction participates in the onset of chronic hypoxic pulmonary hypertension. Am J Physiol Lung Cell Mol Physiol 290: L11-L20, 2006.

13. Wang H: Pharmacological characteristics of the novel antihypertensive drug, iptakalim hydrochloride, and its molecular mechanisms. Drug Dev Res 58: 65-68, 2003.

14. Xie W, Wang H, Wang H and Hu G: Effects of iptakalim hydrochloride, a novel $\mathrm{K}_{\mathrm{ATP}}$ channel opener, on pulmonary vascular remodeling in hypoxic rats. Life Sci 75: 2065-2076, 2004.

15. Xie W, Wang H, Ding J, Wang $\mathrm{H}$ and Hu G: Anti-proliferating effect of iptakalim, a novel $\mathrm{K}_{\mathrm{ATP}}$ channel opener, in cultured rabbit pulmonary arterial smooth muscle cells. Eur J Pharmacol 511: 81-87, 2005.

16. Oltvai ZN, Milliman CL and Korsmeyer SJ: Bcl-2 heterodimerizes in vivo with a conserved homolog, Bax, that accelerates programmed cell death. Cell 74: 609-619, 1993.

17. Yin XM, Oltvai ZN and Korsmeyer SJ: BH1 and BH2 domains of $\mathrm{Bcl}-2$ are required for inhibition of apoptosis and heterodimerization with Bax. Nature 369: 321-323, 1994. 
18. Humbert M, Sitbon O, Chaouat A, Bertocchi M, Habib G, Gressin V, Yaici A, Weitzenblum E, Cordier JF, Chabot F, Dromer C, Pison C, Reynaud-Gaubert M, Haloun A, Laurent M, Hachulla E and Simonneau G: Pulmonary arterial hypertension in France: Results from a national registry. Am J Respir Crit Care Med 173: 1023-1030, 2006.

19. Peacock AJ, Murphy NF, McMurray JJ, Caballero L and Stewart S: An epidemiological study of pulmonary arterial hypertension. Eur Respir J 30: 104-109, 2007.

20. Duffels MG, Engelfriet PM, Berger RM, van Loon RL, Hoendermis E, Vriend JW, van der Velde ET, Bresser P and Mulder BJ: Pulmonary arterial hypertension in congenital heart disease: An epidemiologic perspective from a Dutch registry. Int J Cardiol 120: 198-204, 2007.

21. van de Veerdonk MC, Marcus JT, Westerhof N, de Man FS, Boonstra A, Heymans MW, Bogaard HJ and Vonk NA: Signs of right ventricular deterioration in clinically stable patients with pulmonary arterial hypertension. Chest 147: 1063-1071, 2015.

22. Zhang S, Li G, Tian L, Guo Q and Pan X: Short-term exposure to air pollution and morbidity of COPD and asthma in East Asian area: A systematic review and meta-analysis. Environ Res 148: $15-23,2016$.

23. Hassoun PM, Mouthon L, Barberà JA, Eddahibi S, Flores SC, Grimminger F, Jones PL, Maitland ML, Michelakis ED, Morrell NW, et al: Inflammation, growth factors, and pulmonary vascular remodeling. J Am Coll Cardiol 54 (Suppl): S10-S19, 2009.

24. Stenmark KR, Tuder RM, El KK: Metabolic reprogramming and inflammation act in concert to control vascular remodeling in hypoxic pulmonary hypertension. J Appl Physiol (1985) 119: 1164-1172, 2015.

25. Li P, Oparil S, Sun JZ, Thompson JA and Chen YF: Fibroblast growth factor mediates hypoxia-induced endothelin - a receptor expression in lung artery smooth muscle cells. J Appl Physiol 1985 95: 643-651, discussion 863, 2003.

26. Davie N, Haleen SJ, Upton PD, Polak JM, Yacoub MH, Morrell NW and Wharton J: ET(A) and ET(B) receptors modulate the proliferation of human pulmonary artery smooth muscle cells. Am J Respir Crit Care Med 165: 398-405, 2002.
27. Sato K, Morio Y, Morris KG, Rodman DM and McMurtry IF: Mechanism of hypoxic pulmonary vasoconstriction involves ET(A) receptor-mediated inhibition of K(ATP) channel. Am J Physiol Lung Cell Mol Physiol 278: L434-L442, 2000.

28. Sweeney M, Yu Y, Platoshyn O, Zhang S, McDaniel SS and Yuan JX: Inhibition of endogenous TRP1 decreases capacitative $\mathrm{Ca}^{2+}$ entry and attenuates pulmonary artery smooth muscle cell proliferation. Am J Physiol Lung Cell Mol Physiol 283: L144-L155, 2002.

29. Hu HL, Zhang ZX, Zhao JP, Wang T and Xu YJ: Effect of opening of mitochondrial ATP-sensitive $\mathrm{K}^{+}$channel on the distribution of cytochrome $\mathrm{C}$ and on proliferation of human pulmonary arterial smooth muscle cells in hypoxia. Sheng Li Xue Bao 58: 262-268, 2006 (In Chinese).

30. Hu HL, Wang T and Zhang ZX: The effect on the change of oxygen free radicals and cell proliferation in hypoxic human pulmonary artery smooth muscle cells by mitochondrial membrane potential. Chin J Tubercul Respiratory Diseases 11: 727-730, 0000 (In Chinese).

31. Hu HL, Wang T, Zhang ZX, Zhao JP and Xu YJ: Effect of diazoxide on change of $\mathrm{H}_{2} \mathrm{O}_{2}$ in rat pulmonary artery smooth muscle cells and proliferation of hypoxic rat pulmonary artery smooth muscle cells. Chin J Pathophysiol 23: 2002-2006, 2007 (In Chinese).

32. Hu HL, Wang $\mathrm{T}$ and Zhang ZX: The effect on the distribution of cytochrome $\mathrm{C}$ and cell proliferation in hypoxic rat pulmonary artery smooth muscle cells by mitochondrial membrane potential. Proceedings of Huazhong University of Science and Technology (Medicine) pp166-169,280, 2008 (In Chinese).

33. Zeng H, Kong X, Peng H, Chen Y, Cai S, Luo H and Chen P. Apoptosis and $\mathrm{Bcl}-2$ family proteins, taken to chronic obstructive pulmonary disease. Eur Rev Med Pharmacol Sci 16: 711-727, 2012. 